\title{
Resource utilization and competition among the five Hawaiian species of Trapezia (Crustacea, Brachyura)
}

\author{
Michael E. Huber ${ }^{1} \&$ Stephen L. Coles ${ }^{2}$ \\ ${ }^{1}$ Scripps Institution of Oceanography, A-002, La Jolla, California 92093, USA \\ ${ }^{2}$ University Petroleum and Minerals, UPM Box 802, Dhahran 31261, Saudi Arabia
}

\begin{abstract}
Crabs of the genus Trapezia and their hosts, the reef corals Pocillopora spp., were collected at 2 sites on the island of Oahu, Hawaii. At one site, Kahe Point, all 5 Hawailan species of Trapezia were common, while at Kaneohe Bay, the other site, only $T$. intermedia and $T$ digitalis were abundant. More than $90 \%$ of corals at both sites were inhabited by at least 1 species of Trapezia. Crabs usually occurred as heterosexual pairs, with a single pair of a given species per coral head. Up to 5 species were found to co-occur on single coral colonies. T. intermedia is abundant on coral colonies of all sizes, but the other species of Trapezia are largely restricted to colonies larger than 2000 to $4000 \mathrm{~cm}^{3}$, probably as a result of their aggressive exclusion from small colonies by $T$ intermedia. Histograms of host size frequency do not support a previous worker's conclusion that Hawaiian species of Trapezia segregate the host coral resource according to colony size. Log-linear analysis of species cooccurrence frequencies shows no significant interactions among species except in small colonies. It is hypothesized that territory size exceeds that needed to supply a crab pair's resource requirements. Strong intraspecific territoriality, and a reduction of interspecific territoriality, may allow the coexistence of competing species of Trapezia even if there is overlapping resource utilization.
\end{abstract}

\section{INTRODUCTION}

Since the development of the competitive exclusion principle (Lotka 1925, Volterra 1926, Hutchinson 1957), a great deal of study has been devoted to mechanisms which allow the sympatric coexistence of competing species. Much of this work has focused on resource partitioning, whereby species reduce competition by subdividing limiting resources (Pianka 1976). Mechanisms other than resource partitioning, however, may permit stable coexistence of competitors. For example, Vance (1984) has presented a model in which 2 species competing for the same resource can coexist if interference competition is more intense within than between species. For natural examples of Vance's model, we might look to groups of species which are likely competitors and in which interference competition is important. One such group is the genus Trapezia (Crustacea, Brachyura).

Xanthid crabs of the genus Trapezia are all obligate symbionts of pocilloporid corals (Cnidaria, Scleractinia) (Knudsen 1967). The crabs gain both nutrition, in the form of coral mucus and entrapped particulate material, and protection from predators from the coral host (Barry 1965, Knudsen 1967, Patton 1974 , Wolodarsky 1979). At least in some cases, their relation with the host is mutualistic: the crabs will defend the host coral from the predatory starfish Acanthaster planci (Pearson \& Endean 1969, Glynn 1976). Host corals are common on reefs from the Red Sea to the Eastern Tropical Pacific, and at most sites nearly all host colonies are occupied by at least one species of Trapezia (Crane 1947, Barry 1965, Newell 1971, Garth 1973a, b, Patton 1974, Abele \& Patton 1976, Wolodarsky 1979, Austin et al. 1980, Edwards \& Emberton 1980, Castro 1982).

The species of Trapezia are very similar morphologically except in their distinct, conspicuous color patterns; coloration is often the most reliable means of separating species (Barry 1965, Serène 1969, Patton 1974, Castro 1982). The species are also very similar in behavior. Adults nearly always occur as heterosexual pairs, with a single pair of a given species per coral colony, regardless of colony size (see Castro 1976 and 
Huber 1983 for reviews). The strict pairing and sole occupation of a colony by a pair are maintained by aggressive intraspecific territoriality. While crabs vigorously defend their hosts against adult conspecifics of the same sex (Huber 1983), juveniles are tolerated. Interspecific relations are also mediated by aggressive behavior, though crabs may tolerate adults of other species (Huber 1983).

Because the species of Trapezia are very similar in microhabitat, diet, behavior, and morphology, species which occur sympatrically are potential competitors. In a study of the 5 Hawaiian species of Trapezia, Preston $(1971$ 1973) concluded that these species differ in the sizes of host coral colonies they inhabit, thus segregating the coral resource. Preston also found that a number of species pairs co-occur on coral heads less frequently than would be expected on the basis of chance, presumably because of interspecific agonistic behavior. In this study we examine the host and interspecific relations of the Hawaiian species of Trapezia. We place particular emphasis on the roles of competition and territoriality in the ecology of Hawaiian Trapezia.

\section{MATERIALS AND METHODS}

Collections were made at 2 sites. At Kahe Point, Oahu, 158 colonies of Pocillopora meandrina were collected from 6 stations in the vicinity of the offshore outfall of the Kahe Generating Station. A general description of the area can be found in Jokiel \& Coles (1974) and Coles (1984). Station depths range from 2.5 to $7 \mathrm{~m}$, and abundances of $P$. meandrina were similar at the 6 stations. Corals were collected at approximately 3 mo intervals from January 1976 to July 1977. The second site, described by Huber (1983), was a large reef flat area in Kaneohe Bay, Oahu. A general description of the Kaneohe Bay coral environment is provided by Maragos (1972). From this area, $133 \mathrm{col}-$ onies of $P$. meandrina, $P$. verrucosa, and $P$. ligulata were collected during May and early June of 1979 and late June and July of 1980

At both sites coral colonies were enclosed in plastic bags and broken from the substrate with a chisel or rock hammer, or broken off and placed in buckets, by a diver using SCUBA or snorkelling equipment. Abele \& Patton (1976) found the 2 collecting techniques to be quantitatively equivalent. Corals were then immediately brought to the surface. An effort was made to sample corals which included the entire size range of the species present at the site, and in this sense corals were not sampled randomly. The colonies were returned to the laboratory, where they were either processed immediately or frozen for storage and processed within $3 \mathrm{mo}$.
We measured to the nearest $\mathrm{cm}$ the length of the coral colony along the longest axis in the horizontal plane, the width at the widest point in the horizontal plane perpendicular to the long axis, and the vertical height of the colony. We measured only the diameter of some colonies which were nearly hemispherical, and we excluded the dead bases of the colonies from the measurement of colony size. In some cases the coral colony shattered during collection of transport and was not measured. We did not measure some colonies collected from Kaneohe Bay during 1979.

After measuring the coral colonies, we fragmented them and removed and identified all Trapezia to species with the key of Serène (1969). We recorded the presence or absence of eggs on female crabs. For Kaneohe Bay specimens, we measured carapace width $(\mathrm{Cw})$ at the widest point to the nearest $0.1 \mathrm{~mm}$. For specimens from Kahe Point, we measured $\mathrm{cw}$ to the nearest $1 \mathrm{~mm}$ and wet weight to the nearest $0.1 \mathrm{~g}$.

We calculated coral colony volume by the formula:

colony volume $=(1 / 2) 1 / 3 \pi(1 / 2 \mathrm{~L})(1 / 2 \mathrm{~W}) \mathrm{H}=1 / 6 \pi \mathrm{LWH}$ (1)

where $\mathrm{L}=$ colony length; $\mathrm{W}=$ colony width; $\mathrm{H}=$ colony height. This corresponds to the volume of a hemi-ellipsoid, which is the geometric shape most closely approximated by heads of Pocillopora meandrina. For colonies which were nearly hemispherical, we measured only the diameter (D) of the colony, and calculated colony volume as the volume of a hemisphere: colony volume $=1 / 12 \pi D^{3}$. Our measure of colony size should be highly correlated with measures used by other workers (see Huber 1983).

Crabs were considered to be mature if they were larger than or equal in size to the smallest gravid female of that species. Finney \& Abele (1981) found the size of the smallest gravid female to be a good approximation of the size at sexual maturity. Only adult crabs are considered in the present study, except where otherwise noted.

To test for associations among the Hawaiian species of Trapezia, we examined the pattern of co-occurrence of the 5 species at Kahe Point using the log-linear method of Whittam \& Siegel-Causey (1981). As the first step in the analysis, the null hypothesis of no interaction between species, or the mutual independence model, is tested. When the mutual independence model is rejected, 2 models of species co-occurrence are constructed. The 'lower limit' model incorporates the minimum number of interactions between species which allow an adequate fit to the data. The upper limit model includes any interactions which significantly improve the fit of the model. Whittam \& SiegelCausey (1981) supply a more detailed explanation of the use of log-linear models in examining patterns of species co-occurrence, and technical discussions of the 
statistical methods can be found in Bishop et al. (1975), Everitt (1977), and Goodman (1978).

In addition to using the entire data set from Kahe Point, we also performed analyses excluding (1) all colonies less than $2000 \mathrm{~cm}^{3}$ and (2) all colonies less than $4000 \mathrm{~cm}^{3}$ in order to investigate the effects of colony size. We added 0.5 to each cell before analysis to reduce bias due to low expected values, and used the likelihood ratio statistic, G (Sokal \& Rohlf 1969) as the test statistic for the fit of all models.

Following the convention used by Whittam \& SiegelCausey (1981), the mutual independence model for 5 species, A through $\mathrm{E}$, will be called A, B, C, D, E; a model with a significant interaction between species $A$ and $B$ would be called $A B, C, D, E$. Note that $A B$ includes the main effects of species $A$ and $B$, as well as their interaction.
Correlation and regression analysis, analysis of variance (ANOVA), analysis of covariance (ANCOVA), and $\log$-linear analysis of species co-occurrence were carried out with SPSS version 8.1, SPSSX versions 2.0 and 2.1, and BMDP programs $4 \mathrm{~F}$ and $5 \mathrm{R}$.

\section{RESULTS}

At both sites, more than $90 \%$ of the corals collected were inhabited by at least one species of Trapezia. On a given coral colony, crabs may occur as a single individual, as a heterosexual pair, as 2 or more individuals of the same sex, or in groups of 3 or more with representatives of both sexes. The heterosexual pair was the dominant mode of occurrence of Trapezia spp. (Table 1). When more than one conspecific of the same

Table 1. Mode of occurrence of Trapezia spp. Listed are the absolute numbers of occurrences observed in each category, followed by percent occurrence in parentheses

\begin{tabular}{|c|c|c|c|c|}
\hline \multirow[t]{2}{*}{ Site and species } & \multicolumn{4}{|c|}{ Occurrences of adult Trapezia spp. as: } \\
\hline & Single crab & Heterosexual pair & 2 crabs of same sex & 3 or more crabs \\
\hline \multicolumn{5}{|l|}{ Kaneohe Bay } \\
\hline$T$. intermedia & $12(9.0 \%)$ & $105(78.4 \%)$ & $3(2.2 \%)$ & $14(10.4 \%)$ \\
\hline$T$ digitalis & $17(25.4 \%)$ & $46(68.6 \%)$ & $0(0 \%)$ & $4 \quad(6.0 \%)$ \\
\hline \multicolumn{5}{|l|}{ Kahe Point } \\
\hline T. intermedia & $24(18.6 \%)$ & $84(65.1 \%)$ & $1(0.7 \%)$ & $20(15.5 \%)$ \\
\hline$T$. digitalis & $5(6.9 \%)$ & $52(72.2 \%)$ & $0(0 \%)$ & $15(20.8 \%)$ \\
\hline T. ferruginea & $20(31.7 \%)$ & $39(61.9 \%)$ & $0(0 \%)$ & $4(6.3 \%)$ \\
\hline T. wardi & $20(26.0 \%)$ & $50(64.9 \%)$ & $0(0 \%)$ & $7(9.1 \%)$ \\
\hline T. flavomaculata & $9(27.3 \%)$ & $21(63.6 \%)$ & $0(0 \%)$ & $3(9.1 \%)$ \\
\hline
\end{tabular}

\section{T. INTERMEDIA}

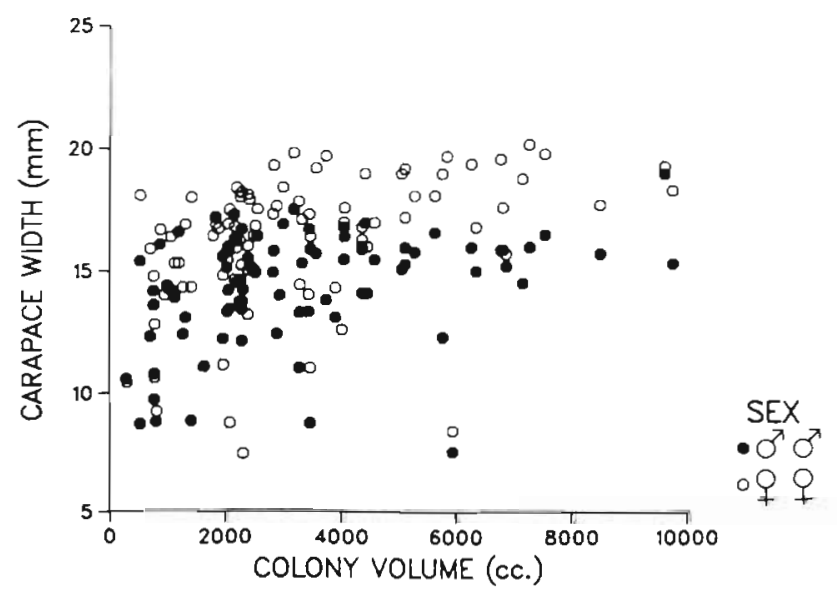

I. DIGITALIS

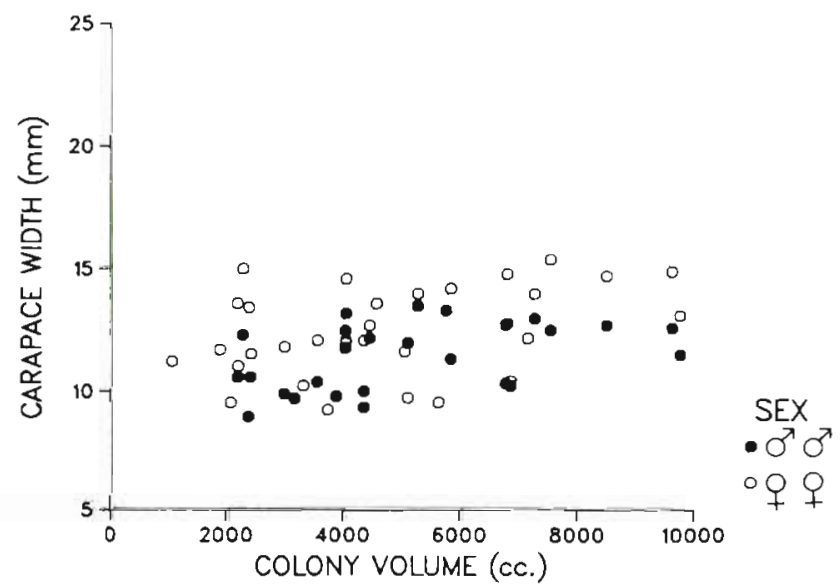

Fig. 1. Trapezia intermedia and $T$. digitalis. Carapace width (cw) of crabs from Kaneohe Bay plotted as a function of host coral colony volume. Model I linear regression equations and Pearson's correlation coefficients, $r$, are as follows: $T$. intermedia males: $c w=13.22+0.00037$ colony volume, $r=0.346(\mathrm{p}<0.01) ; T$. intermedia females: $c w=14.30+0.00057$ colony volume, $r=$ $0.436(p<0.001) ; T$. digitalis males: $c w=9.19+0.00033$ colony volume, $r=0.397(p<0.05) ; T$. digitalis females: $c w=10.86+$ 0.00032 colony volume, $r=0.388(p<0.05)$ 


\section{T. INTERMEDIA}

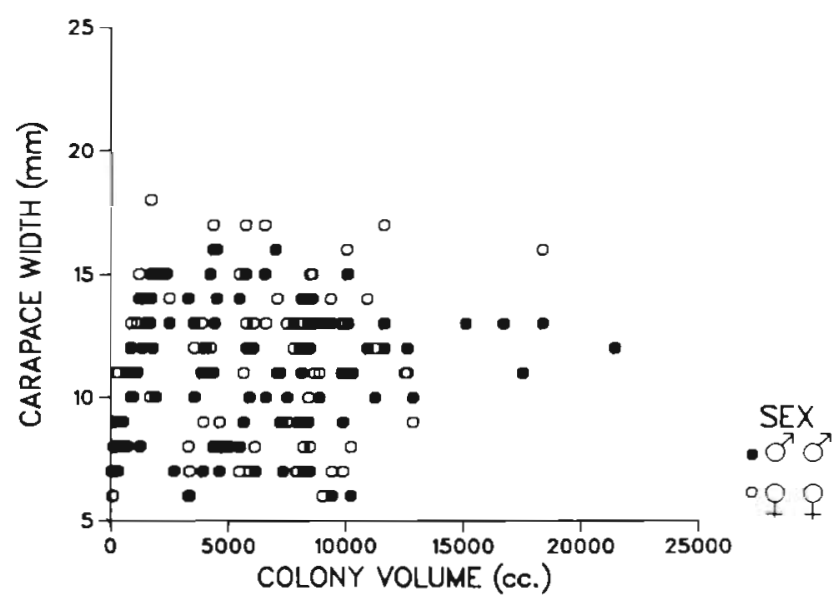

\section{T. FERRUGINEA}

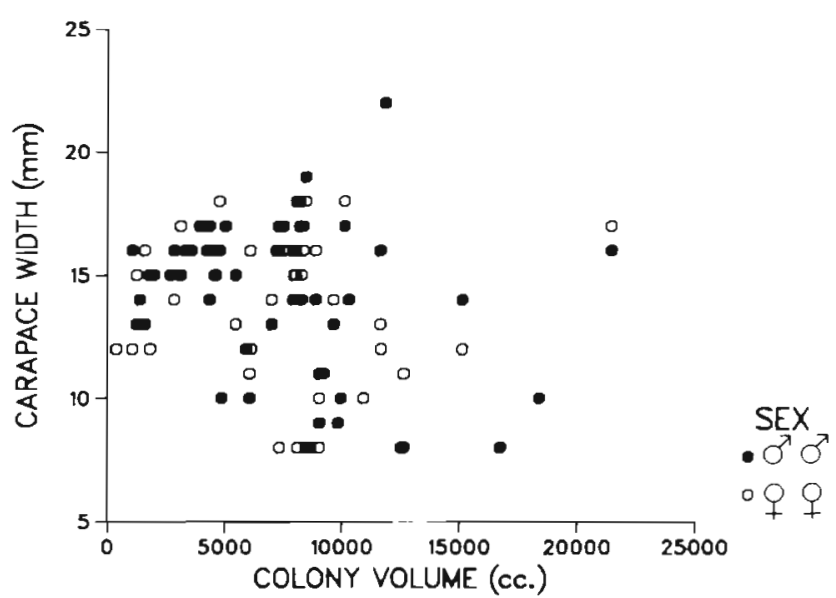

\section{T. FLAVOMACULATA}

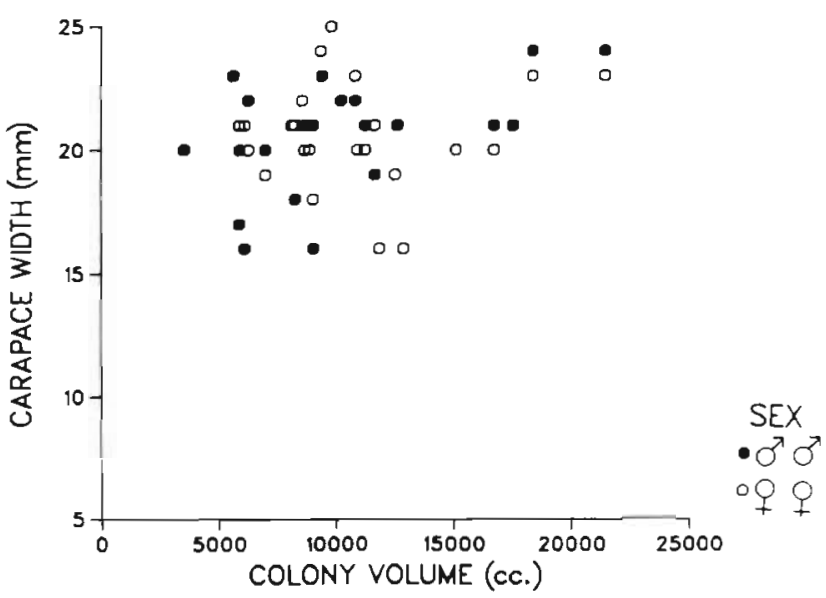

T. DIGITALIS

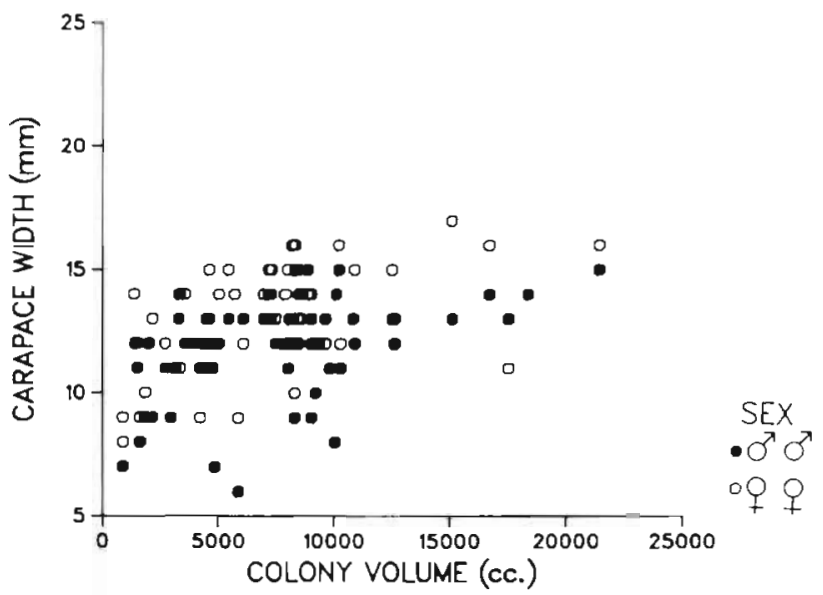

T. WARDI

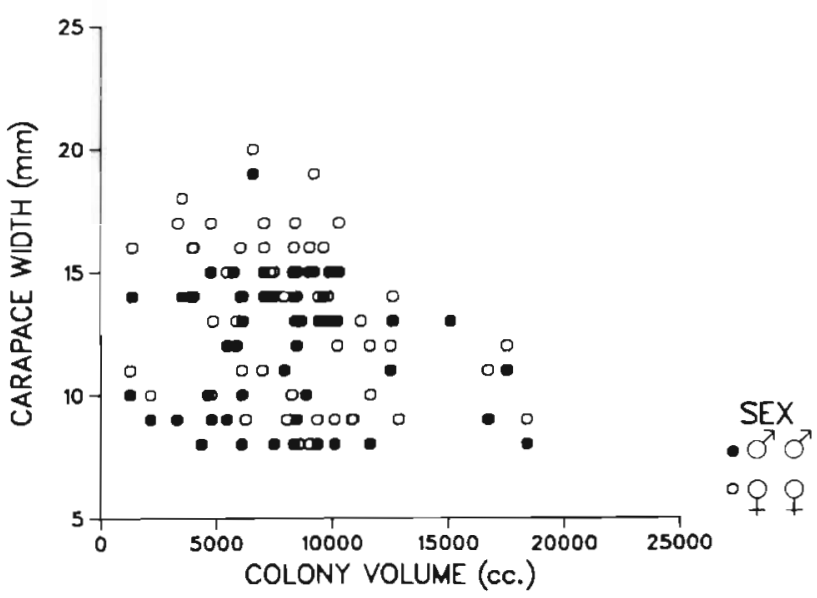

Fig. 2. Trapezia spp. Carapace width of crabs from Kahe Point plotted as a function of host coral colony volume. Model I linear regression equations and Pearson's correlation coefficients, $r$, are as follows: $T$. intermedia males: $\mathrm{CW}=10.40+$ 0.00007 colony volume, $r=0.135(p>0.05) ; T$. intermedia females: $c w=10.59+0.00012$ colony volume, $r=0.189$ $(\mathrm{p}<0.05) ; T$ digitalis males: $\mathrm{CW}=10.59+0.00017$ colony volume, $r=0.416(\mathrm{p}<0.001) ; T$ digitalis females: $c w=$ $12.01+0.00011$ colony volume, $r=0.272(\mathrm{p}<0.05) ; T$ ferruginea males: $c w=15.40-0.00016$ colony volume, $r=$ $-0.235(p>0.05) ; T$ ferruginea females: $c w=14.82-$ 0.00011 colony volume, $I=-0.136(\mathrm{p}>0.05) ; T$ wardi males: $\mathrm{cW}=12.62-0.00007$ colony volume, $r=-0.093$ $(\mathrm{p}>0.05) ; T$ wardi females: $c W=15.20-0.00024$ colony volume, $r=-0.276(\mathrm{p}<0.05)$; $T$. flavomaculata males: $\mathrm{cW}=$ $19.40+0.00010$ colony volume, $r=0.300(\mathrm{p}>0.05) ; T$ flavomaculata females: $c w=20.62+0.00002$ colony volume,

$$
r=0.037(\mathrm{p}>0.05)
$$


sex were found on a colony, one of them was usually considerably larger than the other(s), and injuries to the smaller crabs were common. Host colonies in these cases were usually at the larger end of the spectrum.

Crab size and host colony size were significantly correlated in Trapezia intermedia (except males from Kahe Point), $T$, digitalis and $T$. wardi females (Fig. 1 \& $2)$. Even when correlations were significant, the proportion of variance in $\mathrm{CW}$ accounted for by colony size, as indicated by $r^{2}$, was less than 0.2. In $T$. intermedia, $T$. digitalis, and $T$. ferruginea, crab $\mathrm{CW}$ appeared to increase relatively rapidly with colony volume up to some fairly small colony size and remain constant thereafter. For each species except $T$. flavomaculata, in which sample size was small, we examined the plot of $C W$ vs colony volume (Fig. $1 \& 2$ ) and visually selected a boundary between subsets of small and large colonies. For $T$. intermedia, this boundary was $3000 \mathrm{~cm}^{3}$, for $T$. ferruginea, $4000 \mathrm{~cm}^{3}$, and for $T$. digitalis and $T$. wardi, $5000 \mathrm{~cm}^{3}$. In $T$. intermedia, $T$. ferruginea, and $T$. digitalis males from Kahe Point, there was a significant positive relation between $C W$ and colony volume in small colonies, and the regression slopes and correlation coefficients are higher in small than in large colonies (Table 2). No significant relation between $\mathrm{cW}$ and colony volume was observed in large colonies for any species. For $T$. digitalis from Kahe Point, a secondorder polynomial regression model gave a significantly better fit to the data than a simple linear model (ANOVA; males $p<0.05$, females: $p<0.001$ ).

At Kaneohe Bay, there was no significant effect of coral host species upon crab size (Table 3), and in subsequent analyses data from the 3 host species are pooled. Trapezia intermedia from Kaneohe Bay which co-occurred with other species of Trapezia (mostly $T$. digitalis) were significantly larger than were $T$. intermedia which occurred in the absence of other species of Trapezia (Table 3).

At both sites, there was a significant increase in the total number of adult Trapezia per colony as colony

Table 2. Results of regressions of crab carapace width vs host colony volume within small and large colonies. Size boundaries between small and large colonies, determined by inspection of Fig. 1 \& 2, are $3000 \mathrm{~cm}^{3}$ for Trapezia intermedia, $4000 \mathrm{~cm}^{3}$ for $T$ ferruginea, and $5000 \mathrm{~cm}^{3}$ for $T$ digitalis and $T$. wardi. $\mathrm{N}$ : number of crabs inhabiting corals in each category; b: regression slope; $r$ : Pearson's correlation coefficient; $\mathrm{p}$ : probability that the true correlation coefficient, $\mathrm{Q}$, equals 0 ( $t$-test). Codes for $\mathrm{p}$ are as follows: $\cdots p<0.001 ; \cdots p<0.01 ; \cdot \mathrm{p}<0.05$; ns: $\mathrm{p}>0.05 . T$ flavomaculata was not included because of small sample size

\begin{tabular}{|c|c|c|c|c|c|c|c|c|c|c|}
\hline \multirow[t]{2}{*}{ Site } & \multirow[t]{2}{*}{ Species } & \multirow[t]{2}{*}{ Sex } & \multicolumn{4}{|c|}{ Small colonies } & \multicolumn{4}{|c|}{ Large colonies } \\
\hline & & & $\mathrm{N}$ & b & $r$ & $\mathrm{p}$ & $\mathrm{N}$ & $\mathrm{b}$ & r & $\mathrm{p}$ \\
\hline \multirow{4}{*}{ Kaneohe Bay } & $T$ intermedia & $\mathrm{m}$ & 47 & 0.0015 & 0.50 & $\cdots$ & 37 & 0.0003 & 0.25 & ns \\
\hline & & $\mathrm{f}$ & 50 & 0.0014 & 0.37 & $\cdot$ & 40 & 0.0004 & 0.31 & ns \\
\hline & $T$ digitalis & $\mathrm{m}$ & 18 & 0.0010 & 0.48 & ns & 13 & -0.0003 & -0.26 & ns \\
\hline & & $\mathrm{f}$ & 19 & 0.0001 & 0.05 & ns & 14 & 0.0006 & 0.50 & ns \\
\hline \multirow[t]{8}{*}{ Kahe Point } & $T$ intermedia & $\mathrm{m}$ & 33 & 0.0024 & 0.68 & $\cdots$ & 74 & 0.0000 & 0.06 & ns \\
\hline & & $\mathrm{f}$ & 35 & 0.0037 & 0.84 & $\cdots$ & 74 & 0.0000 & 0.07 & ns \\
\hline & $T$. digitalis & $\mathrm{m}$ & 24 & 0.0007 & 0.48 & $\cdot$ & 42 & 0.0001 & 0.22 & ns \\
\hline & & $\mathrm{f}$ & 22 & 0.0003 & 0.22 & ns & 43 & 0.0000 & -0.08 & ns \\
\hline & T. ferruginea & $\mathrm{m}$ & 12 & 0.0009 & 0.68 & $\cdot$ & 38 & -0.0002 & -0.20 & ns \\
\hline & & $\mathrm{f}$ & 12 & 0.0012 & 0.74 & • & 41 & -0.0001 & -0.11 & ns \\
\hline & T. wardi & $\mathrm{m}$ & 11 & 0.0001 & 0.03 & ns & 43 & -0.0002 & -0.25 & ns \\
\hline & & $\mathrm{f}$ & 10 & 0.0004 & 0.19 & ns & 50 & -0.0003 & -0.26 & ns \\
\hline
\end{tabular}

Table 3. Trapezia spp. Results of analysis of covariance of carapace width vs sex, host species, and, for $T$. intermedia, occurrence with other species of Trapezia, using host coral colony volume as the covariate. Data from Kaneohe Bay. Codes for probability, p, are those used in Table 2

\begin{tabular}{|llrrll}
\hline Species & Factor & F (df) & p & Comment \\
\hline \multirow{2}{*}{ T. intermedia } & Sex & $28.30(1,154)$ & $\ldots$ & Males smaller \\
& Host species & $2.68(2,154)$ & $n$ ns & Crabs co-occurring with other \\
& Co-occurrence & $12.67(1,154)$ & $\cdots$ & species are larger \\
& & & & Males smaller \\
T. digitalis & Sex & $12.36(1,57)$ & ns & \\
& Host species & $2.46(2,57)$ & & \\
\hline
\end{tabular}


size increased (Fig. 3). There was a significant difference between Kahe and Kaneohe in the slopes of the regressions of the number of adults on colony size ( $t$ test, $p<0.01)$. The regressions of crab number on colony size did not differ significantly among host species at Kaneohe Bay (ANCOVA; $p>0.05$ ).

\section{KANEOHE BAY}

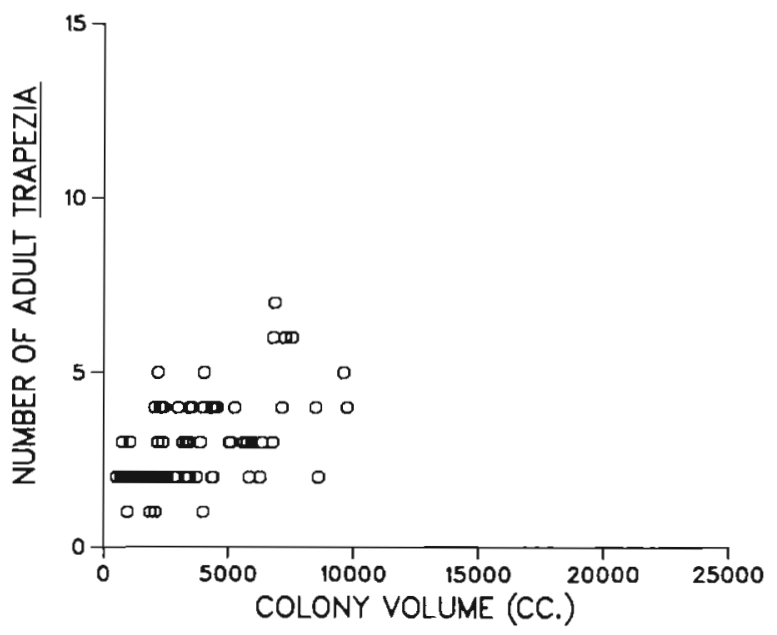

Trapezia intermedia was very common on colonies of all sizes, while the other species are more or less restricted to hosts larger than about $2000 \mathrm{~cm}^{3}$ (Fig. 4). Whether small colonies were excluded from the analysis or not, the observed distribution of species differed significantly from a null hypothesis of no interaction

Fig. 3. Trapezia spp Number of adults inhabiting a coral colony at Kaneohe Bay and Kahe Point, Hawaii, plotted as a function of host coral colony volume. At Kaneohe Bay, crab no. $=1.75+0.00030$ colony volume (Model I linear regression). $95 \%$ confidence limits for the slope are \pm 0.00010 . Pearson's correlation coefficient, $r=0.544(\mathrm{p}<0.0001)$. At Kahe Point, crab no. $=$ $1.71+0.00049$ colony volume. $95 \%$ confidence limits for the slope are $\pm 0.00006, r=0.756(p<0.0001)$

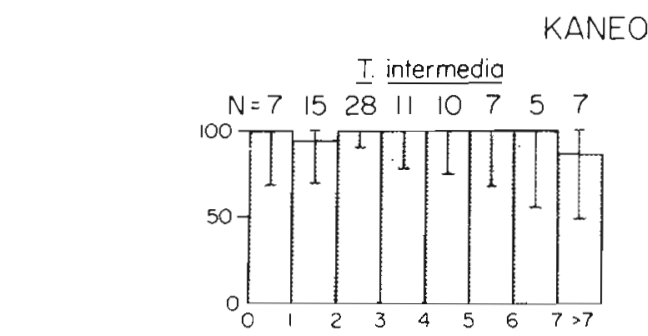

KANEOHE BAY

KAHE POINT

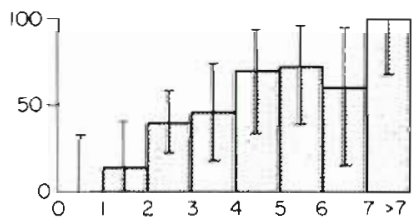

I. digitalis

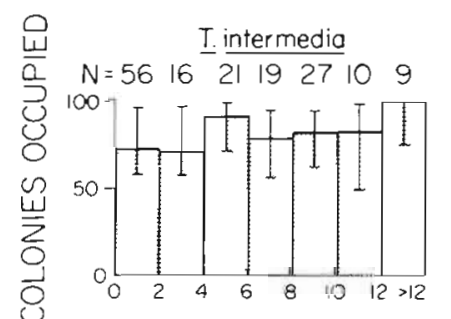

I ferrugined

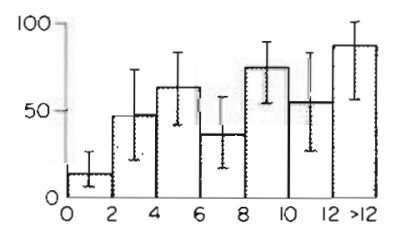

I. flovomaculata
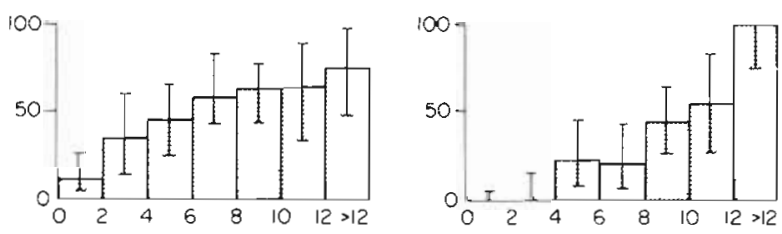

COLONY VOLUME $\left(1 \mathrm{O}^{3} \mathrm{CC}\right)$
KAHE POINT

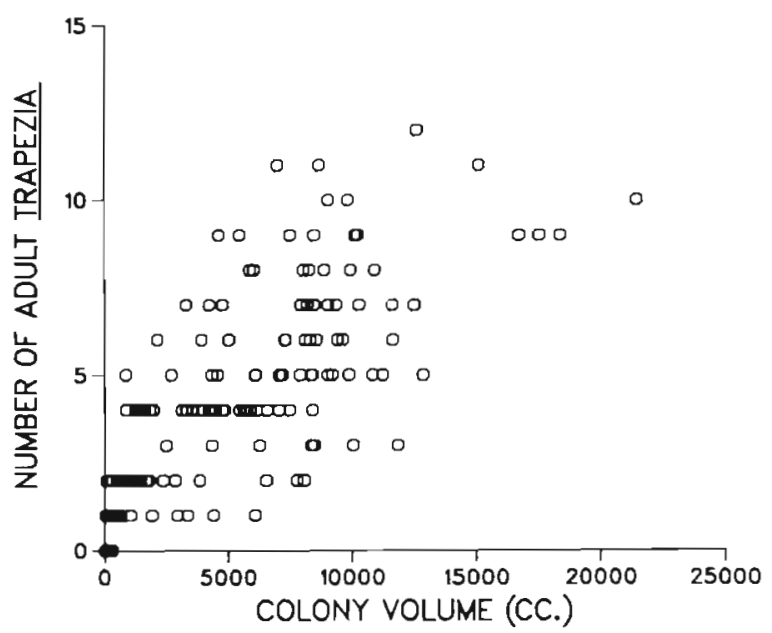


between species, that is, from the mutual independence model (Table 4). Therefore, interactions among species must be invoked to account for the observed species distributions. The lower limit models of Table 4 show the fewest interactions which must be included to produce a model which does not differ significantly from the data. In all 3 lower limit models, $T$. intermedia was distributed independently of the other species, and all significant interactions between the other species were positive, that is, the species pairs involved co-occurred more frequently than would be expected on the basis of chance. No upper limit models could be constructed when colonies smaller than $2000 \mathrm{~cm}^{3}$ or $4000 \mathrm{~cm}^{3}$ were excluded because no interactions other than those included in the lower limit models were significant. In the upper limit model for all colonies, there is one significant negative interaction, between $T$. intermedia and $T$. ferruginea.

Most females were gravid at both sites (Table 5). The proportion of gravid females did not appear to vary with season or colony size.

\section{DISCUSSION}

A number of workers have found significant linear relations between aspects of the Pocillopora symbiont community and the size of coral heads (Abele 1976, Abele \& Patton 1976, Woldarsky 1979, Austin et al.

Table 4. Fit of log-linear models of species interaction to observed frequencies of co-occurrence of the 5 Hawaiian species of Trapezia at Kahe Point. Analysis was performed on the entire data set and on 2 subsets: only colonies larger than $2000 \mathrm{~cm}^{3}$ and only colonies larger than $4000 \mathrm{~cm}^{3}$. See text for explanation of notation used to designate models. Species abbreviations: int $=$ $T$. intermedia; $\operatorname{dig}=T$. digitalis; fer $=T$. ferruginea; $w r d=T$. wardi; $f l v=T$. flavomaculata. Codes for probability, $p$, are those used in Table 2

\begin{tabular}{|c|c|c|c|c|c|c|}
\hline Data set & & Model & & $G$ & $\mathrm{df}$ & $p$ \\
\hline & & Mutual independence & & & & \\
\hline All colonies & & int, dig, fer, wrd, flv & & 96.64 & 26 & $\cdots$ \\
\hline Colonies $>2000 \mathrm{~cm}^{3}$ & & int, dig, fer, wrd, flv & & 47.37 & 26 & $\cdots$ \\
\hline \multirow[t]{3}{*}{ Colonies $>4000 \mathrm{~cm}^{3}$} & & int, dig, fer, wrd, flv & & 39.10 & 26 & - \\
\hline & & Lower limit & & & & \\
\hline & Independent & $\begin{array}{c}\text { Positive } \\
\text { interactions }\end{array}$ & $\begin{array}{c}\text { Negative } \\
\text { interactions }\end{array}$ & & & \\
\hline All colonies & int & $\begin{array}{c}\text { dig-fer, dig-flv } \\
\text { wrd-flv }\end{array}$ & None & 31.02 & 23 & $\mathrm{~ns}$ \\
\hline Colonies $>2000 \mathrm{~cm}^{3}$ & int, wrd, flv & dig-fer & None & 29.71 & 25 & $\mathrm{~ns}$ \\
\hline \multirow[t]{3}{*}{ Colonies $>4000 \mathrm{~cm}^{3}$} & int, wrd, flv & dig-fer & None & 25.90 & 25 & ns \\
\hline & & Upper limit & & & & \\
\hline & Independent & $\begin{array}{c}\text { Positive } \\
\text { interactions }\end{array}$ & $\begin{array}{l}\text { Negative } \\
\text { interactions }\end{array}$ & & & \\
\hline All colonies & None & $\begin{array}{l}\text { dig-fer, dig-flv, } \\
\text { fer-wrd, wrd-flv }\end{array}$ & int-fer & 21.83 & 21 & ns \\
\hline Colonies $>2000 \mathrm{~cm}^{3}$ & & Same as lower limit & & & & \\
\hline Colonies $>4000 \mathrm{~cm}^{3}$ & & Same as lower limit & & & & \\
\hline
\end{tabular}

Table 5. Trapezia spp. Percent of adult females gravid. Confidence limits (CL) are from Rohlf \& Sokal (1981: Table 23)

\begin{tabular}{|c|c|c|c|c|}
\hline Site & Species & $\%$ Gravid & $95 \% \mathrm{CL}$ & $N$ \\
\hline Kaneohe Bay & $\begin{array}{l}T . \text { intermedia } \\
T \text {. digitalis }\end{array}$ & $\begin{array}{l}94.2 \\
83.0\end{array}$ & $\begin{array}{l}88.9-97.4 \\
71.1-91.4\end{array}$ & $\begin{array}{r}137 \\
59\end{array}$ \\
\hline Kahe Point & $\begin{array}{l}T . \text { intermedia } \\
T . \text { digitalis } \\
T . \text { ferruginea } \\
T \text { wardi } \\
T . \text { flavomaculata }\end{array}$ & $\begin{array}{l}83.3 \\
84.7 \\
86.0 \\
73.5 \\
91.2\end{array}$ & $\begin{array}{l}75.3-89.6 \\
69.1-94.3 \\
73.2-94.2 \\
61.6-83.3 \\
76.6-98.1\end{array}$ & $\begin{array}{r}114 \\
72 \\
50 \\
68 \\
34\end{array}$ \\
\hline
\end{tabular}


1980, Coles 1980, Edwards \& Emberton 1980, Gotelli \& Abele 1983, Huber 1983, Abele 1984, Adams et al. 1985, Gotelli et al. 1985). Our data suggest that in Trapezia spp. the relation between crab size and host size is not linear, but rather that the crabs increase in size with increasing coral size only up to a point, crab size remaining more or less constant thereafter. Barry (1965) found a similar asymptotic relation between the size of Trapezia intermedia and the size of the Pocillopora meandrina host in Hawaii. Thus, at least above a certain colony size, the size of Trapezia spp. is probably not strongly determined by colony size or resources related to colony size.

Abele \& Patton (1976), Wolodarsky (1979), and Adams "et al. (1985) report significant linear correlations between the sizes of coral heads and their resident Trapezia spp., but do not present sufficient information to allow determination of whether a linear or curvilinear model is most appropriate.

It is not surprising that the size of resident crabs remains largely constant with increasing colony size above some small colony size. Barry (1965) found that the branching pattern of Pocillopora meandrina in Hawaii is such that the distance between branches remains constant as the colony increases in size. Thus, the Pocillopora habitat changes quantitatively, but not qualitatively, as the coral head increase in size (Barry 1965, Abele \& Patton 1976, Austin et al. 1980). Clearly, a continuous increase in the size of the crabs would soon restrict their ability to move among the branches of the coral, since the distance between branches does not increase with colony size. This mobility is of great importance in feeding and during intra- and interspecific interactions (Glynn 1976, Lassig 1977, Huber 1983).

The upper size limit of the crabs does not, then, appear to be constrained by energetic or nutritional requirements, except perhaps in small colonies. This conclusion should be confirmed by further study. Though the nature of the relation between coral net productivity and colony size has not been established, it seems reasonable that food resources resulting from coral production should increase with increasing colony size. External surface area, skeletal mass and displacement volume, 'habitat space' (the total amount of space between the branches), and colony volume have been found to be strongly positively intercorrelated (Barry 1965, Abele 1976, Abele \& Patton 1976, Austin et al. 1980), and it is expected that the live surface area should be similarly related. Thus, while the distance between branches remains constant, the photosynthetically active surface area, mucus production, and the area available to capture suspended particulates, and therefore the food available to Trapezia spp., should increase with increasing colony size. If so, either food resources beyond the needs of single crab pairs are available in large colonies, or the metabolic requirements of the crabs increase with increasing coral size independently of the size of the crabs.

The dominant occurrence of heterosexual pairs corroborates the findings of other workers (see 'Introduction'). Pairing is apparently maintained by intraspecific aggressive behavior, as crabs residing on a coral colony vigorously repel conspecifics of the same sex (Huber 1983), and the frequency of agonistic behavior could increase with colony size. Intruding crabs are either small crabs which have settled from the plankton and recently reached sexual maturity or sexually mature crabs immigrating from other colonies. Newly mature crabs are small and probably can be easily evicted by large residents. The rate of intercolony movement by adults is unknown. Castro's (1978) observations of substantial movement in laboratory experiments probably do not reflect natural rates, because his experiments included crabs later recognized as 3 distinct species (Castro 1982, pers. comm.). Furthermore, the presence of potentially predatory fish apparently reduced the rate of movement (Castro 1978). When substantial movement between colonies has been observed, colonizing crabs are mostly juveniles or small adults, and often bear injuries which probably reduce their aggressive ability (Huber 1983, Abele 1984). Territorial energy expenditures therefore probably represent only a small part of the overall energy budget of resident crabs.

The increased resource available in large colonies might also be utilized in elevated reproductive effort, particularly by females. The number of eggs produced is highly correlated with the size of females (Preston 1971, Gotelli et al. 1985). Because crab size and colony size are poorly correlated, the correlation between crab size and clutch size should be reduced if clutch size varies with colony size. Thus, the number of eggs produced per clutch is probably not a strong function of colony size.

Other workers have found, as in the present study, that most female Trapezia spp. are gravid, and that egg production is year round (Crane 1947, Barry 1965, Wolodarsky 1979, Edwards \& Emberton 1980, Gotelli et al. 1985), though Gotelli et al. (1985) do report seasonal variation in egg production in $T$. corallina. The development time of a clutch is about $1 \mathrm{mo}$, and the interval between the hatching of one clutch and the extrusion of another is 1 to $2 \mathrm{~d}$ (M.E.H. pers. obs., P. Castro pers. comm.). Egg size appears to be more or less constant (Preston 1971). Female reproductive output, then, does not appear to depend on colony size, though it is possible that egg quality varies with host size.

If the requirements of the resident crabs do not keep 
pace with the increased resources made available by colony growth, 'excess' resource will be made available. The significant correlation between the number of crabs inhabiting a coral colony and colony volume reflects increased resource availability on large colonies. Since pairs defend even large hosts against adult conspecifics, but will tolerate other species of Trapezia, the increase in the number of crabs on large colonies is accomplished mainly by the addition of species. Four of the 5 species are more common on larger hosts. At Kaneohe, there are essentially only 2 species present, and more than 4 adults can coexist only on the rare occasions when multiple conspecifics of the same sex co-occur. Therefore, one would expect it to be much more difficult to add crabs as the colony grows at Kaneohe than at Kahe, where the pool of potential colonizers includes 5 species. The significantly greater slope of the crab number vs colony size regression at Kahe Point than at Kaneohe Bay is therefore consistent with the greater number of species at Kahe Point.

As mentioned previously, the species of Trapezia are likely competitors because of their ecological and morphological similarity. Preston $(1971,1973)$ proposed that the 5 Hawailan Trapezia species segregate by host colony size, some species being specialized for large and some for small hosts. The results of the present study do not support this view. For example, $T$. intermedia does not specialize on small hosts but occurs with more or less constant frequency over the entire range of host size. The frequency distributions of the sizes of hosts inhabited by the other Hawaiian species are clearly not normal, as claimed by Preston (1971, 1973).

If the species of Trapezia are in strong competition, negative associations between species are expected. Only one negative species interaction, between $T$. intermedia and $T$. ferruginea, was observed, and it is not necessary to include this interaction to obtain a model which adequately fits the data. Patterns of cooccurrence of Hawaiian Trapezia species can be explained largely in terms of the species' host-size distributions. In the lower-limit models $T$. intermedia, abundant on hosts of all sizes, is distributed independently of the other species. The other species are more or less restricted to heads larger than about $2000 \mathrm{~cm}^{3}$, and therefore are positively associated in the loglinear models of species co-occurrence. When smaller colonies are excluded from the analysis only the association between $T$. digitalis and $T$. ferruginea remains significant.

Preston (1973) found significant negative associations between several pairs of Hawaiian Trapezia species. Unlike the present study, Preston combined data from a number of sites, and Preston tested for species interactions by performing a series of pairwise contingency analyses, rather than testing for all interactions simultaneously, as we have done.

The relative rarity of species other than Trapezia intermedia on small colonies probably reflects strong territoriality rather than an inability of the other species to inhabit small hosts. Juveniles of all species except $T$. flavomaculata were found on colonies in all size classes, and juvenile abundance does not appear to vary with coral head size except in T. flavomaculata (authors' unpubl. data). It seems likely that individuals of $T$. intermedia drive away all congeners, and thereby dominate, in small colonies. Barry (1965) stated that $T$. intermedia is the most aggressive species. Interspecific territoriality is common and can be as intense as intraspecific territoriality. $T$. intermedia and $T$. wardi, for example, display intense mutual aggression (Huber 1983) and exert a strong negative influence upon each other's size when they co-occur (Barry 1965). As the colony grows above a size where live coral tissue area is no longer a limiting resource, newly arrived congeners, but not conspecifics, are tolerated. $T$. flavomaculata seems to be an exception, for $T$. flavomaculata is a very large species found only on large colonies, and juveniles are more abundant on large colonies (authors' unpubl. data). The relatively small size of the coral colonies collected in Kaneohe Bay, compared to those from Kahe Point, may explain the rarity of $T$. ferruginea, $T$. wardi, and $T$. flavomaculata at the Kaneohe Bay site.

An alternate hypothesis is that some minimal size difference between individual crabs, rather than a minimum colony size, is required to mitigate interspecific aggression. This hypothesis is supported by the observation that, at Kaneohe Bay, individuals of $T$. intermedia which co-occur with other species of Trapezia are significantly larger than $T$. intermedia which occur alone, even when the effects of colony size are factored out.

Huber (1983) has discussed a number of factors which in theory might result in a selective advantage for crabs which defend colonies larger than needed to meet the crabs' resource requirements. Several workers have concluded that the intraspecific territorial behavior of the crabs acts to hold their numbers below the resource-imposed limit (Barry 1965, Preston 1971, 1973, Patton 1974, Abele \& Patton 1976). This view seems to fit Vance's (1984) model in which 2 species competing for the same limiting resource can coexist if intraspecific interference competition is stronger than interspecific interference competition. Thus, mechanisms which reduce aggression among, but not within, species of Trapezia could allow the coexistence of the species on colonies even in the absence of differences in resource utilization. The conspicuous differences 
between species in coloration may act to reduce interspecific aggression.

Acknowledgements. We are grateful for the advice and technical assistance of P. Castro, J. Enright, M. Gilpin, P. Jokiel, L. Lutz, W. Newman, A. Yayanos, and the staff of the Hawaii Institute of Marine Biology. Travel to and work in Hawaii by M.E.H. was supported by grants from the Pauley Foundation. Statistical analyses were performed on the University of California, San Diego, VAX-VMS computer.

\section{LITERATURE CITED}

Abele, L. G. (1976). Comparative species richness in fluctuating and constant environments: coral associated decapod crustaceans. Science, N.Y. 191: 461-463

Abele, L. G. (1984). Biogeography, colonization, and experimental community structure of coral-associated crustaceans. In: Strong, D. R., Jr., Simberloff, D., Abele, L. G. Thistle, A. B. (ed.) Ecological communities: conceptual issues and the evidence. Princeton Univ. Press, p. 123-137

Abele, L. G., Patton, W. K. (1976). The size of coral heads and the community biology of associated decapod crustaceans. J. Biogeogr. 3: 35-47

Adams, J., Edwards, A. J., Emberton, H. (1985). Sexual size dimorphism and assortative mating in the obligate coral commensal Trapezia ferruginea Latreille (Decapoda, Xanthidae). Crustaceana 48: 188-194

Austin, A. D., Austin, S. A., Sale, P. F. (1980). Community structure of the fauna associated with the coral Pocillopora damicornis (L.) on the Great Barrier Reef. Aust. J. mar. Freshwat. Res. 31: 163-174

Barry, C. K. (1965). Ecological study of the decapod crustaceans commensal with the branching coral Pocillopora meandrina var. nobilis Verrill. M.S. thesis. University of Hawaii, Honolulu

Bishop, Y. M. M., Fienberg, S. E., Holland, P. W. (1975). Discrete multivariate analysis: theory and practice. MIT Press, Cambridge, Massachusetts

Castro, P. (1976). Brachyuran crabs symbiotic with scleractinian corals: a review of their biology. Micronesica 12: 99-110

Castro, P. (1978). Movements between coral colonies in Trapezia ferruginea (Crustacea: Brachyura), an obligate symbiont of scleractinian corals. Mar. Biol. 46: 237-245

Castro, P. (1982). Notes on symbiotic decapod crustaceans from Gorgona Island, Columbia, with a preliminary revision of the eastern Pacific species of Trapezia (Brachyura, Xanthidae), symbionts of scleractinian corals. An. Inst. Inv. Mar. Punta de Betin (Anales del Instituto de Investigaciones Marinas de Punta de Betin) 12: 9-17

Coles, S. L. (1980). Species diversity of decapods associated with living and dead reef coral Pocillopora meandrina. Mar. Ecol. Prog. Ser. 2: 281-291

Coles, S. L. (1984). Colonization of Hawaiian reef corals on new and denuded substrata in the vicinity of a Hawaiian power station. Coral Reefs 3: 123-130

Crane, J. (1947). Eastern Pacific expeditions of the New York Zoological Society. XXXVII. Intertidal brachygnathous crabs of the west coast of tropical America with special reference to ecology. Zoologica, N.Y. 32: 69-95

Edwards, A., Emberton, H. (1980). Crustacea associated with the scleractinian coral, Stylophora pistillata (Esper), in the Sudanese Red Sea. J. exp. mar. Biol. Ecol. 42: 225-240

Everitt, B.S. (1977). The analysis of contingency tables. Chapman and Hall, London
Finney, W. C., Abele, L. G. (1981). Allometric variation and sexual maturity in the obligate coral commensal Trapezia ferruginea Latreille (Decapoda, Xanthidae). Crustaceana 41: $113-130$

Garth, J. S. (1973a). Decapod crustaceans inhabiting reefbuilding corals of Ceylon and the Maldive Island. J. mar. biol. Ass. India 15: 195-212

Garth, J. S. (1973b). The brachyuran crabs of Easter Island. Proc. Calif. Acad. Sci. 39: 311-336

Glynn, P. W. (1976). Some physical and biological determinants of coral community structure in the Eastern Pacific. Ecol. Monogr. 46: 431-456

Goodman, L. A. (1978). Analyzing qualitative/categorical data. Abt Books, Cambridge, Massachusetts

Gotelli, N. J., Abele, L. G. (1983). Community patterns of coral-associated decapods. Mar. Ecol Prog. Ser. 13: 131-139

Gotelli, N. J., Gilchrist, S. L., Abele, L. G. (1985). Population biology of Trapezia spp. and other coral-associated decapods. Mar. Ecol. Prog. Ser. 21: 89-98

Huber, M. E. (1983). Ethology and population biology of Trapezia, a xanthid crab symbiotic with reef corals, with special reference to territoriality and speciation. Ph. D thesis, Scripps Inst. Oceanogr., Univ. Calif., San Diego

Hutchinson, G. E. (1957). Concluding remarks. Cold Spring Harbour Symp. Quant. Biol. 22: 415-427

Jokiel, P. L., Coles, S. L. (1974). Effects of heated effluent on hermatypic corals at Kahe Point, Oahu. Pacif. Sci. 28: 1-18

Knudsen, J. W. (1967). Trapezia and Tetralia (Decapoda, Brachyura, Yanthidael as obligate ectoparasites of pocilloporid and acroporid reef corals. Pacif. Sci. 21: 51-57

Lassig, B. R. (1977). Communication and coexistence in a coral community. Mar. Biol. 42: 85-92

Lotka, A. J. (1925). Elements of physical biology. Williams and Wilkens, Baltimore

Maragos, J. E. (1972). A study of the ecology of Hawaiian reef corals. Ph. D. thesis, University of Hawaii, Honolulu

Newell, N. D. (1971). An outline history of tropical organic reefs. Am. Mus. Novit. 2465: 1-37

Patton, W. K. (1974). Community structure among the animals inhabiting the coral Pocillopora damicomis at Heron Island, Australia. In: Vernberg, W. B. (ed.) Symbiosis and the sea. Univ. S. Carolina Press, Columbia, p. 219-243

Pearson, R. G., Endean, R. (1969). A preliminary study of the coral predator Acanthaster planci (L.) (Asteroidea) on the Great Barrier Reef. Queens. Dept. Harbours and Marine, Fish. Notes 3: 27-55

Pianka, E. R. (1976). Competition and niche theory. In: May, R. M. (ed.) Theoretical ecology principles and applications. W. B. Saunders, Philadelphia, p. 142-162

Preston, E. M. (1971). Niche overlap and competition among five sympatric congeneric species of xanthid crabs. Ph. D. thesis, University of Hawaii, Honolulu

Preston, E. M. (1973). A computer simulation of competition among five sympatric congeneric species of xanthid crabs. Ecology 54: 469-483

Rohlf, F. J., Sokal, R. R. (1981). Statistical tables, 2nd edn. W. H. Freeman, San Francisco

Serène, R. (1969). Observations on species of the group Trapezia rufopunctata-maculata, with a provisional key for all the species of Trapezia. J. mar. biol. Ass. India 11 . $126-148$

Sokal, R. R., Rohlf, F. J. (1969). Biometry. W. H. Freeman, San Francisco

Vance, R. R. (1984). Interference competition and the coexistence of two competitors on a single limiting resource. Ecology 65: 1349-1357 
Verner, J. (1977). On the adaptive significance of territoriality. Am. Nat. 111: 769-775

Volterra, V. (1926). Variazioni e fluttuazioni del numero d'individui in specie animali conviventi. Mem. Aced. Lincei 2 31-113

Whittam, T. S., Siegel-Causey, D. (1981). Species interactions and community structure in Alaskan seabirds. Ecology 62 $1515-1524$

Wolodarsky, Z. (1979). Population dynamics of Trapezia crabs inhabiting the coral Stylophora pistillata in the northern Gulf of Eilat (Red Sea). M. Sc. thesis, Tel Aviv Univ. (English summary)

This article was submitted to the editor; it was accepted for printing on February 10, 1986 